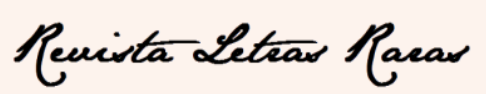

ISSN: $2317-2347$ - v. 8, n. 3 (2019)

\title{
Pareceristas ad. hoc.
}

\author{
Ediçãa: u. 8, u. 3, 2019
}

\section{Adriana Lúcia de Escabar Chaves de Barras}

Possui pós-Doutorado em Letras Modernas pela USP (2016-2017). É Doutora em Estudos da Linguagem pela PUC-Rio (2010). Mestre em Administração de Empresas com especialização em Marketing pelo IAG Escola de Negócios da PUC-Rio (2006). Diplomada no curso de pós-graduação em Management (MBA) pelo IAG Escola de Negócios da PUC-Rio (2003). Diplomada no curso de pós-graduação em Metodologia do Ensino da Língua Inglesa. Possui o DOTE - Diploma for Overseas Teachers of English pela Universidade de Cambridge, Inglaterra (1994), adquirindo o título de Royal Society of Arts -RSA. Licenciada em Letras Português-Inglês Licenciatura Plena pela PUC-Rio (1984). Atualmente é professora efetiva da Universidade Estadual do Mato Grosso do Sul, ministrando aulas nos cursos de graduação e de pós-graduação stricto sensu do Mestrado Acadêmico e Profissional em Letras. Foi tesoureira da ALAB (Associação Brasileira de Linguística Aplicada) no biênio 2014-2015. Foi professora da Universidade Anhanguera-Uniderp, em Campo Grande, Mato Grosso do Sul na graduação dos cursos de Administração e Publicidade e Propaganda e na pós-graduação lato sensu no curso de MBA (2010- 2011) e assumiu a coordenação do curso de Publicidade e Propaganda em 2011. Trabalhou na Cultura Inglesa Rio (1986-2009), onde foi professora, coordenadora pedagógica e gerente de filial (1993-2009). Foi professora de classe de alfabetização, de inglês no Ensino Fundamental e em instituições particulares de Língua Inglesa (19791998). Tem experiência profissional nas seguintes áreas: Estudos da Linguagem com ênfase em Linguística Aplicada e Sociolinguística; Administração Escolar, com ênfase em Gestão Organizacional e Gestão de Pessoas; e Administração de Empresas, com ênfase em Comunicação Empresarial, Marketing, Liderança e Negociação. Atualmente, suas áreas de interesse são: Sociolinguística Interacional / Variacionista e Linguística Aplicada, com foco em Ensino de Línguas, Formação de Professores, Línguas de Comunidades Minoritárias e (De)colonialidade, Fronteiras, Língua, Cultura e Identidade.

http://lattes.cnpq.br/0201552127514276

\section{Ana Karina de Oliveira Nascimento}

É graduada em Letras (Português/Inglês) pela Universidade Federal de Sergipe - UFS (1999), especialista em Ensino de Inglês pela UFMG (2003), mestre em Educação pela UFS (2007) e doutora em Letras (Estudos Linguísticos e Literários em Inglês) pela Universidade de São Paulo (USP), período no qual foi bolsista CNPq de doutorado no país. Foi bolsista Capes/Fulbright de doutorado sanduíche na Montclair State University, 


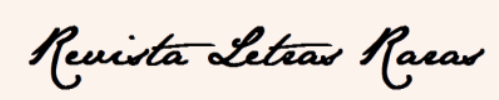

ISSN: $2317-2347$ - v. 8, n. 3 (2019)

em Montclair, New Jersey, EUA, durante 9 meses, sob orientação da profa. Michele Knobel. Atualmente é professora efetiva da Universidade Federal de Sergipe, atuando na graduação em Letras Inglês e Português/Inglês. É coordenadora da área de Inglês do Programa Institucional de Bolsa de Iniciação à Docência (PIBID/CAPES/UFS). Faz parte do grupo de Pesquisa Letramentos em Inglês: Língua, literatura e Cultura (UFS). Tem experiência na área de Letras, com ênfase em Língua Inglesa, atuando principalmente nos seguintes temas: formação de professores de inglês, letramentos digitais, linguística aplicada, ensino de língua inglesa.

http://lattes.cnpq.br/6730704244662630

\section{Ana Paula Martinez Dubac}

Possui graduação em Letras pela Universidade Federal de São Carlos, Mestrado em Estudos Linguísticos e Literários em Inglês pela Universidade de São Paulo e Doutorado pelo mesmo programa com período sanduíche na University of Manitoba, Winnipeg, Canadá. Atualmente é docente do Departamento de Metodologia do Ensino e Educação Comparada da Faculdade de Educação da Universidade de São Paulo, sendo responsável pela disciplina Metodologia do Ensino de Inglês. No Programa de Pós-Graduação da FEUSP, atua na área temática "Educação, Linguagem e Psicologia". Tem interesse nos seguintes temas: ensino e aprendizagem de línguas estrangeiras, avaliação da aprendizagem de línguas, letramento(s), multiletramentos, letramento crítico, formação de professores de línguas, teorias pós-modernas e pós-coloniais.

http://lattes.cnpq.br/8933339247096718

\section{Angélica Aracija de Mela Maia}

Professora de ensino superior - Possui graduação em Habilitação II - Língua Inglesa e Língua Portuguesa pela Universidade Federal da Paraíba (1992) e mestrado em Letras pela Universidade Federal de Pernambuco (1995). Concluiu em 2009 um segundo mestrado na Universidade da Columbia Britânica (Canadá) na área de Estudos Educacionais. Concluiu o Doutorado em Educação na Universidade Federal da Paraíba Programa de Pós-graduação em Educação na linha de Políticas Educacionais em fevereiro de 2014. Atua como professora de Estágio Supervisionado no Departamento de Letras Estrangeiras Modernas da Universidade Federal da Paraíba desde abril de 2012, na área específica de formação docente para a educação básica, e exerce a função de Coordenadora da Área de Estágio Supervisionado do curso de Letras (Inglês, Francês e Espanhol) desde outubro de 2013. Foi coordenadora do subprojeto PIBID Letras- Inglês da UFPB de março de 2014 a abril de 2017. Foi vice-diretora voluntária da Casa Pequeno Davi, instituição socioeducacional de apoio a crianças e adolescentes na cidade de João Pessoa, PB, Brasil. Vice-coordenadora dos Cursos de Letras Presenciais da UFPB desde 


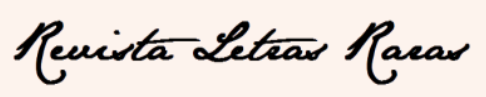

ISSN: $2317-2347$ - v. 8, n. 3 (2019)

abril de 2017. Foi coordenadora institucional do Programa Institucional de Bolsa de Iniciação à Docência da UFPB de março a outubro de 2018. No presente ano (2019), atua como Post-Doctoral Fellow na Universidade da Columbia Britânica, Canada / The University of British Columbia, BC, Canada.

http://lattes.cnpq.br/9890924477786909

\section{Ciela Griselda Festina}

Cielo G. Festino é doutora em literatura indiana de língua inglesa pela USP. Fez um programa de pós-doutorado sobre o conto nas línguas vernáculas da Índia, de autoria feminina, na Universidade Federal de Minas Gerais (2010-2012). É professora de literaturas de língua inglesa na Universidade Paulista, São Paulo e professora colaboradora do programa de Mestrado da Universidade Federal de Tocantins. É membro do projeto temático Pensando Goa. Uma Biblioteca Singular em Língua Portuguesa (USP/FAPESP). Tem várias publicações sobre literatura indiana, entre elas foi co-editora do volume da revista literária Muse India (vol. 70, 2016), dedicado à literatura de Goa de língua portuguesa, do do livro A House of Many Mansions: Goan Literature in the Portuguese Language. An Anthology of Original Essays, Short Stories and Poems (Margão, Goa: Under the Peepal Tree, 2017) e do volume "Goans on the Move" da Interdisciplinary Journal of Portuguese Diaspora Studies (Vol. 7, 2018).

http://lattes.cnpq.br/7581931650490028

\section{Daniel Ferrag}

Daniel Ferraz é pós-doutor pela Universidade de São Paulo, com pesquisa focalizada em educação em língua inglesa. Possui Doutorado em Estudos Linguísticos e Literários em Inglês pela Universidade de São Paulo (2012) focalizado na educação de língua inglesa e novas tecnologias. Parte da pesquisa de doutorado foi realizada na Universidade de Manitoba ? Canadá por meio do programa de doutorado sanduíche da CAPES. Possui Mestrado em Letras Inglês na área de Letramento Visual pela Universidade de São Paulo (2006) e Graduação em Letras pela Pontifícia Universidade Católica de São Paulo (2002). Atualmente, desenvolve pesquisas nas áreas dos novos letramentos, novas tecnologias e critical and visual literacies e tem publicado artigos e capítulos de livros nas áreas mencionadas.Tem experiência na área de Letras, com ênfase em Línguas Estrangeiras Modernas,

http://lattes.cnpq.br/1090255590865526 


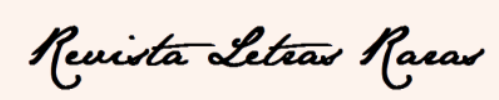

ISSN: $2317-2347$ - v. 8, n. 3 (2019)

\section{Dianei Mathias}

Professor de língua e literatura na Universidade Federal de Santa Maria. Possui formação em Letras pela Universidade de Hamburgo (Grund- und Hauptstudium, Magister Artium, Doktor phil.) e pela Universidade Federal do Paraná (Doutorado em Letras).

http://lattes.cnpq.br/0718781986349346

\section{Damingas Sávia Pimentel Siqueira}

Doutor em Letras e Linguística pela Universidade Federal da Bahia, Professor Associado II do Instituto de Letras da UFBA. Como linguista aplicado, tenho interesse especial nas seguintes áreas e temas: formação de professores de línguas, Estudos Culturais e Educação Linguística, ensino de inglês como língua internacional (LI) ou língua franca (LF), "World Englishes", abordagens críticas ao ensino de ILI/ILF, sociolinguística da língua inglesa, imperialismo linguístico, estudos pós-coloniais de língua inglesa, pedagogia crítica aplicada ao ensino de línguas, inter(trans)culturalidade e LE, além de práticas reflexivas no ensino e na aprendizagem de línguas. Sou líder certificado do grupo de pesquisa "Inglês como língua franca: crítica, atitude e identidade" e exerci por dois mandatos a Coordenação do Programa de Pós-Graduação em Língua e Cultura da UFBA. Sou professor permanente do PPGLINC-UFBA e do Programa de Mestrado em Letras e Linguística da UFT-Porto Nacional (TO). Na extensão, exerci a Orientação Acadêmica de Língua Inglesa do Núcleo Permanente de Extensão e Pesquisa do Instituto de Letras da UFBA por dez anos e, atualmente, atuo como Coordenador Geral do projeto para o biênio (2018-2020). Conduzi estudos de pós-doutorado dentro das temáticas Inglês como Língua Franca, Pedagogia Crítica e produção de materiais didáticos no Departamento de Estudos de Segunda Língua da Universidade do Havaí, campus Manoa, Honolulu, Havaí, Estados Unidos, com bolsa CAPES-Fulbright (2015-2016).

http://lattes.cnpq.br/7046333198408985

\section{Elgimar Goettenauer de Marins Costa}

Doutora em Letras Neolatinas (Espanhol) pela Faculdade de Letras da Universidade Federal do Rio de Janeiro, UFRJ, com estágio pós-doutoral na USP e na Universidade Pompeu Fabra - Barcelona. Fui professora do Ensino Fundamental e Médio no Rio de Janeiro de 1979 a 2000. Lecionei na Universidade Estadual de Londrina de 2001 a 2004, onde desenvolvi diferentes projetos. Atualmente sou Professora Associada de espanhol na FALE/UFMG. Sou coordenadora dos Projetos de Pesquisa "Práticas de letramentos nos livros didáticos de espanhol aprovados pelo PNLD 2017 e 2018" e "A (des)construção da argumentação no gênero notícia". Minha área de pesquisa abrange formação de professores, avaliação e produção de materiais didáticos e leitura/letramento crítico. Sou 


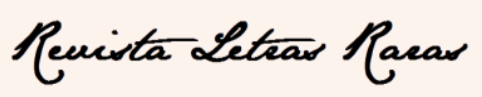

ISSN: $2317-2347$ - v. 8, n. 3 (2019)

co-autora da coleção didática para o Ensino Médio Sentidos en Lengua Española, publicada pela editora Moderna e aprovada pelo PNLD 2018.

http://lattes.cnpq.br/1182169907712352

\section{Girlene Moreira da Silua}

Possui graduação em Letras - Português e Espanhol (2008), mestrado em Linguística Aplicada (2011) e doutorado em Linguística Aplicada (2016) pela Universidade Estadual do Ceará. Atualmente é professora efetiva de língua espanhola do Instituto Federal de Educação, Ciência e Tecnologia do Rio Grande do Norte (IFRN), atuando nos Cursos de Licenciatura em Espanhol dos Campi Natal Central e EaD. Tem experiência em pesquisas na área de Linguística Aplicada, atuando principalmente nos seguintes temas: formação de professores de línguas, crenças, ensino de Espanhol como língua estrangeira, ensino de leitura e uso do texto literário no ensino de línguas estrangeiras.

http://lattes.cnpq.br/8122463467348141

\section{Gabriela Radella de Oliveira}

É bacharela em Letras/Alemão e Português pela Faculdade de Filosofia, Letras e Ciências Sociais da USP $(\mathrm{FFLCH})$, licenciada em Língua Portuguesa, mestra na área de Linguagem e Educação (práticas de leitura literária de professores de português, 2008) e doutora (práticas e representações de leitura literária de adolescentes, 2013) pela Faculdade de Educação da USP (FE-USP). É Professora Adjunta na Universidade Federal do Sul da Bahia (UFSB), sendo atualmente Coordenadora Institucional do Programa de Residência Pedagógica (Capes) da universidade. Atua como orientadora específica no Programa de Pós-Graduação em Educação da FE-USP. É vice-líder do Grupo de Pesquisa Linguagens na Educação (FE-USP), pesquisadora do Grupo de Pesquisa Sociedade, Educação e Universidade (SEU/UFSB) e faz parte da Rede Interdisciplinar e Interinstitucional Êxito Escolar, Empoderamento e Ascensão Social (Rieas). É autora de coleção de livros didáticos de Português para o EF II e para o EM. Tem experiência na área de Educação, com ênfase no ensino de Leitura e Produção de Textos, Literatura e Língua Portuguesa, atuando principalmente nas seguintes áreas: ensino de leitura e produção de textos; ensino de literatura e de leitura literária; formação de professor; alfabetização e oralidade; inovação pedagógica; produção e edição de material didático de português para o ensino básico.

http://lattes.cnpq.br/0903463996787375

\section{Duliana Zeggia Martinez}




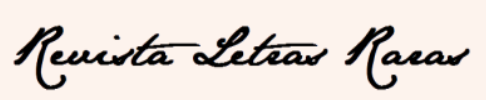

ISSN: $2317-2347$ - v. 8, n. 3 (2019)

Graduada em Letras (Licenciatura Português/Inglês) pela Universidade Federal do Paraná (UFPR), especialista em Linguística Aplicada ao Ensino da Língua Inglesa pela Universidade Estadual do Paraná (UNESPAR), mestre em Letras pela Universidade Federal do Paraná (UFPR) e doutora em Letras pela Universidade de São Paulo (USP) no Programa de Estudos Linguísticos e Literários em Inglês. É professora no Curso de Letras Inglês na Universidade Federal do Paraná onde ministra disciplinas de língua inglesa, educação linguística, linguística aplicada, políticas linguísticas/educacionais bem como cultura e ensino. Atua em projetos de formação inicial e continuada de professores de línguas no Núcleo de Assessoria Pedagógica (NAP) da UFPR. Participa dos grupos de pesquisa: Identidade e Leitura na UFPR e do Projeto Nacional de Letramentos: Linguagem, Cultura, Educação e Tecnologia na USP. Seus interesses de pesquisa voltamse para formação inicial e continuada de professores de línguas, formação internacional e intercultural de professores, educação linguística, letramento crítico, estudos decoloniais e políticas/práticas linguísticas e educacionais. Atualmente desenvolve pesquisa sobre a internacionalização da Educação Superior, o imbricamento entre internacionalização e interculturalidade, a expansão do inglês em contextos universitários e o programa latino-americano de modernidade/colonialidade.

http://lattes.cnpq.br/3955973005266585

\section{Leina Cláudia Viana Zucá}

Licenciada em Letras (Língua Inglesa e suas literaturas) pela Universidade Federal de Minas Gerais (UFMG), Mestre em Linguística Aplicada pela mesma instituição e Doutora em Letras pelo Programa de Pós-Graduação em Estudos Linguísticos e Literários em Inglês, da Universidade de São Paulo (USP). Atualmente é professora no Departamento de Letras da Universidade Federal de Ouro Preto (UFOP), onde trabalha com formação inicial de professores de Língua Inglesa (LI), realiza pesquisa na área de ensino e aprendizagem de LI e nas áreas dos multiletramentos, com ênfase em letramento crítico, aplicados à formação inicial e continuada de professores e ao ensino de LI na graduação e na educação básica. Seus interesses de pesquisa incluem, ainda, questões relacionadas à agência, profissionalismo, cidadania e ética docente e da implicação dessas questões para o (re)posicionamento social, histórico, profissional e político do professor. Ainda na UFOP, é fundadora do Grupo de Estudos sobre Aprendizagem da Docência (GEAD, inscrito no Diretório de Grupos de Pesquisa do CNPq), que reúne licenciandos e professores de línguas em serviço (Inglês, Italiano, Português). Integra, ainda, o grupo de pesquisa Linguagem, Educação, Cultura e Tecnologia (USP), o Núcleo de Estudos Críticos em Linguagens, Educação e Sociedade (UFF) e é membro-fundadora do Núcleo de Estudos Críticos sobre Letramentos, Linguagens e Educação - NECLLE (UFMG), todos igualmente inscritos no Diretório de Grupos de Pesquisa do CNPq. Na área de formação continuada, foi, por um longo período, colaboradora do projeto Educação Continuada em Línguas Estrangeiras (EDUCONLE), da Faculdade de Letras da UFMG. É coautora de livros didáticos para o ensino de inglês, tendo tido duas coleções aprovadas no Programa Nacional do Livro Didático (PNLD) em 2012 e 2015. 


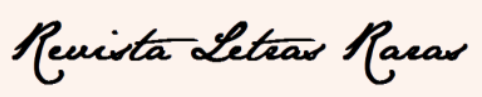

ISSN: $2317-2347$ - v. 8, n. 3 (2019)

http://lattes.cnpq.br/9278798937869761

\section{Livia de Arawjo Dannini Radrigues}

Possui graduação em Letras pela Universidade de São Paulo (1991), graduação em Licenciatura pela Universidade de São Paulo (1992), mestrado e doutorado em Educação pela Universidade de São Paulo (1999 e 2005). Atualmente é docente do Departamento de Metodologia do Ensino e Educação Comparada da Faculdade de Educação da Universidade de São Paulo, onde ministra cursos voltados à Metodologia do Ensino de Língua Inglesa. Tem experiência na área de Educação, com ênfase em Formação de Professores, atuando principalmente nos seguintes temas: formação inicial e continuada de professores, desenho curricular, comunidade profissional e produção de materiais didáticos.

http://lattes.cnpq.br/4537401692636107

\section{Luciana Ferrari de Oliveira Fiarat}

Possui graduação em Letras Inglês e Respectivas Literaturas pela Universidade Federal do Espírito Santo (UFES) (1999), mestrado em TESOL - West Virginia University (2002) e doutorado em Estudos Linguísticos-Inglês pela Universidade de São Paulo (USP). É professora adjunto I do Departamento de Línguas e Letras da Universidade Federal do Espírito Santo. Tem experiência na área de Lingüística Aplicada, atuando nas teorias dos Multiletramentos e Letramento Crítico, Ensino de Línguas Estrangeiras e Formação de Professores.

http://lattes.cnpq.br/7883079654168163

\section{Marca Antânia Margarida Costa:}

Doutor em Letras pela Faculdade de Filosofia, Letras e Ciências Humanas da Universidade de São Paulo (FFLCH/USP), com estágio na Universidade de WisconsinMadison (EUA). Realizou pesquisa de pós-doutorado na FFLCH e na Universidade de York, Toronto (Canadá). Atualmente é professor na Graduação e na Pós-Graduação da Unidade Acadêmica de Letras do Centro de Humanidades da Universidade Federal de Campina Grande (UFCG). Realiza pesquisas em Linguística Aplicada, em especial, na área de Ensino-Aprendizagem de Língua Inglesa, Análise de Discurso, Formação de Professores de Língua Inglesa e Letramentos. Participa do Projeto Nacional Letramentos: Linguagem, Educação, Cultura e Tecnologia, vinculado à Universidade de São Paulo e é membro do Grupo de Pesquisa "Laboratório de Estudos de Letras e Linguagens na Contemporaneidade" (CNPq/UFCG). 


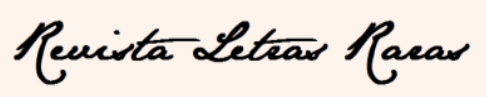

ISSN: $2317-2347$ - v. 8, n. 3 (2019)

http://lattes.cnpq.br/7215425152123749

\section{Maria Amália Vargas Zaçauha}

Doutora em Educação pela Universidade Federal de Sergipe, na linha Educação, Comunicação e Diversidade. Mestre em Educação pela Universidade Federal de Sergipe (UFS), na linha de pesquisa Novas Tecnologias, Educação e Trabalho. Licenciada em Letras Português/Inglês (UFS). Experiência com o ensino de Língua Inglesa, Literaturas de Língua Inglesa e Leitura, Ensino de Inglês e os Letramentos. Pesquisadora dos grupos de pesquisa da USP/UFS: 1. Novos Letramentos, Multiletramentos e o Ensino de Línguas Estrangeiras; 2. Letramentos em Inglês: língua, literatura e cultura. Pesquisadora no grupo de pesquisa da UFS: ECult - Cultura digital na formação de professores em rede.

http://lattes.cnpq.br/3147516241804549

\section{Marlene de Almeida Augusta de Sauza}

Possui graduação em Letras pela Faculdade Ibero Americana (1993), mestrado e doutorado em Estudos Linguísticos e Literários em Inglês pela Universidade de São Paulo (2003/2011). Atuou como professora de escolas públicas estaduais de São Paulo durante 20 anos e como professora de inglês e prática de ensino em cursos de Letras em instituições particulares durante 15 anos. Durante 2 anos e meio foi professora de inglês da FATEC-Carapicuíba. Atualmente é professora efetiva da Universidade Federal de Sergipe. Atua, principalmente, nos seguintes temas: novas tecnologias, multiletramentos críticos, ensino língua estrangeira, escola pública, formação (continuada) de professores.

http://lattes.cnpq.br/0548522187471169

\section{Nara Hiroka Takaki}

Possui Bacharelado em Inglês e Português pela Faculdade de Letras, Filosofia e Ciências Humanas da Universidade de São Paulo, Licenciatura em Inglês e Português pela Faculdade de Educação da Universidade de São Paulo, Mestrado, Doutorado e Pósdoutorado pelo Programa de Pós-Graduação em Estudos Linguísticos e Literários da Universidade de São Paulo. Diploma in Teaching English to Speakers of Other Languages (DELTA). É professora associada da Universidade Federal de Mato Grosso do Sul. Leciona no Curso de Letras e no Programa de Pós-Graduação, Mestrado em Estudos de Linguagens da UFMS. Participa do Mestrado Interdisciplinar em Estudos Culturais da UFMS. Tem experiência na área de Letras, Linguística, com ênfase em Linguística Aplicada. Atua com os seguintes temas: inter-multi-transculturalidades, multi-inter-trans-disciplinaridades, línguas/linguagens e sociedade, interpretação/construção de sentido, translingualismos, novos letramentos, multiletramentos, letramentos críticos, tecnologias aplicadas ao ensino, éticas póscoloniais em ontologias, epistemologias, metodologias de ensino e pesquisa, formação de 


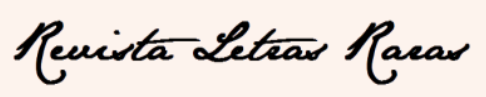

ISSN: $2317-2347$ - v. 8, n. 3 (2019)

professores, material didático. É autora dos livros: 'Leitura na formação de professores de inglês da rede pública: a questão da reprodução de leitura no ensino de inglês' e de 'Letramentos na Sociedade digital: navegar é e não é preciso'. Coautora de Letramentos em Terra de Paulo Freire e de Construções de sentido e letramento digital crítico na área de línguas/linguagens.

http://lattes.cnpq.br/6795089944396694

\section{Rudsan Edsan Gomes de Sauza}

Pós-doutorando, doutor e mestre em Estudos da Linguagem pela Universidade Federal do Rio Grande do Norte (2018/2013/2010); especialista em Mídias na Educação pela Universidade do Estado do Rio Grande do Norte (2013); especialista em Psicopedagogia Institucional pela Universidade Castelo Branco/RJ (2006) e graduado em Letras - dupla licenciatura plena em Português, Inglês e Literaturas pela Universidade Federal do Rio Grande do Norte (1998). Atua/atuou como: professor de Português, Inglês e Intercompreensão na Rede Pública de Ensino da Prefeitura Municipal de Natal, além de assessor pedagógico e formador de professores de Português/Inglês do Ensino Fundamental e Educação de Jovens e Adultos (EJA); professor de Inglês para o Ensino Médio na Rede Pública de Ensino do Governo do Estado do Rio Grande do Norte; formador em Intercompreensão de Línguas Românicas da plataforma de aprendizagem GALAPRO da Universidade de Aveiro/PT; conteudista na Cengage Learning Brasil e no Instituto Federal de Educação, Ciência e Tecnologia (IFRN); escritor na Editora Appris; professor a distância nas disciplinas de Mídias na Educação, Latim II e Linguística I e III do curso de Licenciatura em Espanhol, além de tutor na disciplina de Linguística II, também no IFRN; professor da disciplina de Metodologia da Pesquisa Científica em cursos de pós-graduação da Faculdade Dom Heitor Sales.

http://lattes.cnpq.br/8630828227580690

\section{Simane Batista da Silua}

Doutora em Letras, na área de Estudos Linguísticos e Literários em Inglês, Universidade de São Paulo (USP); Mestre em Educação, Universidade Católica de Petrópolis (UCP); Especialista em Língua Inglesa; Licenciada em Letras. Docente da Universidade Federal Rural do Rio de Janeiro - UFRRJ, atuando na graduação em Letras e no programa de pósgraduação em Educação Agrícola - PPGEA, com a Linha de Pesquisa "Multiletramentos Críticos e Formação de professores de línguas". Líder do GEPELI - Grupo de Estudos e Pesquisas em Ensino de Língua Inglesa, e pesquisadora do Projeto Nacional de Letramentos, do Grupo de Pesquisa "Novos Letramentos, Multiletramentos e o ensino de 


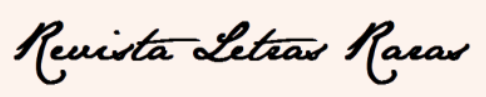

ISSN: $2317-2347$ - v. 8, n. 3 (2019)

línguas estrangeiras", da USP. Editora-chefe da Retta - Revista de Educação Agrícola, do PPGEA/UFRRJ. Tem experiência na área de Letras, com ênfase em Ensino da Língua Inglesa, Multiletramentos e Formação Docente. Desenvolve pesquisa principalmente nos seguintes temas: Ensino de Língua Inglesa, Multiletramentos, Transculturalidade, Discursos Identitários e Formação Docente.

http://lattes.cnpq.br/1985424809328384

\section{Wanderlan da Silua Alues}

É Doutor em Letras (2014) pela Universidade Estadual Paulista \&quot;Júlio de Mesquita Filho\&quot; campus de São José do Rio Preto (UNESP/SJRP), onde também cursou Mestrado em Letras (2011) e Graduação em Letras (Português/Espanhol) (2008). Atualmente, é professor de Literaturas Hispânicas da Universidade Estadual da Paraíba. É membro da Latin American Studies Association (LASA), da Associação Brasileira de Hispanistas $(\mathrm{ABH})$ e dos Grupos de Pesquisa \&quot;Experiência e experimentalismo na narrativa contemporânea\&quot; (UNESP) e \&quot;Trânsitos teóricos e deslocamentos epistêmicos: feminismo(s), estudos de gênero e teoria queer\&quot; (UFSM), do qual é vice-líder. Coordena o Grupo de Estudos de Literatura e Crítica Contemporâneas (GELCCO), cadastrado no CNPq e certificado pela UEPB. É editor-assistente da revista Olho dágua (ISSN 2177-3807) e um dos editores-chefes da revista Sociopoética (ISSN 1980-7856), além de prestar consultarias ad hoc para periódicos nacionais e internacionais. É docente permanente do Programa de Pós-graduação em Literatura e Interculturalidade (PPGLI/UEPB), atuando nas linhas de pesquisa \&quot;Literatura, Memória e Estudos Culturais\&quot; e \&quot;Literatura Comparada e Intermidialidade\&quot;. Seus principais temas de interesse acadêmico são: Narrativa moderna e contemporânea na América Latina, Crítica literária contemporânea na América Latina, Literatura e Cultura de massa, Mixagem de gêneros escriturais e Literatura e Pensamento crítico.

http://lattes.cnpq.br/4245634036144170 